\title{
A Missense Mutation at Codon 188 of the Human Lipoprotein Lipase Gene Is a Frequent Cause of Lipoprotein Lipase Deficiency in Persons of Different Ancestries
}

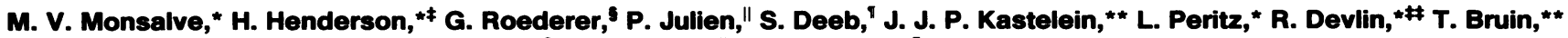 \\ M. R. V. Murthy,"s C. Gagne," J. Davignon," P. J. Lupien," J. D. Brunzell,' and M. R. Hayden* \\ ${ }^{*}$ Department of Medical Genetics, University of British Columbia, Vancouver, V6T 2B5 Canada; ${ }^{\ddagger}$ Department of Chemical Pathology, \\ University of Cape Town, Cape Town, South Africa; ${ }^{\circledR}$ Hyperlipidemia and Atherosclerosis Research Group, Clinical Research Institute \\ of Montreal, Montreal, H2W 1R7 Canada; "Lipid Research Centre, Laval University Hospital, Quebec City, G1V 4G2 Canada; \\ 'Department of Medicine, University of Washington, Seattle, Washington; ${ }^{* *}$ Centre for Thrombosis, Hemostasis and Atherosclerosis, \\ University of Amsterdam, Amsterdam, The Netherlands; " Department of Fisheries and Oceans, West Vancouver, U7V 1 N6 Canada; and \\ $\$$ Department of Biochemistry, Laval University, Quebec City, G1V 4 G2 Canada
}

\begin{abstract}
Lipoprotein lipase (LPL) plays a crucial role in the regulation of lipoprotein metabolism by hydrolysing the core triglycerides of circulating chylomicrons and VLDL. Human, bovine, mouse, and guinea pig complementary DNA clones have recently been isolated and the organization of the human LPL gene is now known to comprise 10 exons spanning $\sim 30 \mathrm{~kb}$.

Here we report a similar mutation on 21 alleles from 13 unrelated affected probands with LPL deficiency of French Canadian, English, Polish, German, Dutch, and East Indian ancestry. We show that an identical missense mutation within exon 5, resulting in an amino acid substitution of glutamic acid for glycine at position 188, is responsible for LPL deficiency in 21 of 88 LPL alleles assessed. This mutation alters an Ava II restriction site in exon 5 and will allow a rapid screening test for this mutation in patients with LPL deficiency. This mutation has occurred on the same haplotype in all the unrelated affected persons suggesting a common origin.

The amino acid substitution lies within the longest segment of homology for LPL in different species and results in a protein that is catalytically defective. (J. Clin. Invest. 1990. 86:728-734.) Key words: lipoprotein lipase $\bullet$ missense mutation $\bullet$ catalysis $\bullet$ ancestral origins
\end{abstract}

\section{Introduction}

The enzyme lipoprotein lipase (LPL) ${ }^{1}$ plays a pivotal role in the hydrolysis of triacylglycerols in plasma lipoproteins. The action of LPL occurs at the luminal surface of vascular endothelium to which it is anchored by a membrane-bound heparan sulfate glycosaminoglycan chain. The synthesis of LPL,

Address reprint requests to Dr. Michael R. Hayden, Department of Medical Genetics, University of British Columbia, RM F168-2211 Wesbrook Mall, Vancouver, BC V6T 2B5 Canada.

Received for publication 1 February 1990 and in revised form 10 May 1990.

1. Abbreviations used in this paper: LPL, lipoprotein lipase; PCR, polymerase chain reaction; RFLP, restriction fragment length polymorphism.

J. Clin. Invest.

(c) The American Society for Clinical Investigation, Inc.

0021-9738/90/09/0728/07 \$2.00

Volume 86, September 1990, 728-734 however, occurs in parenchymal cells, primarily adipose tissue and skeletal muscle, from which it is secreted and transported by an unknown mechanism to the intimal surface of the vascular endothelium. Active LPL is a noncovalently linked homodimer of two glycoprotein chains each of $\sim 50 \mathrm{kD}$ (1). For optimal activity against long-chain triglycerides, LPL requires the presence and binding of apo CII.

Human (2), bovine (3), mouse (4), and guinea pig (5) complementary cDNA clones of LPL show homology of $\sim 83 \%$ (6). The human gene spans $\sim 30 \mathrm{~kb}$ on the short arm of chromosome 8 (7) and comprises 10 exons with exon 10 specifying the entire $3^{\prime}$ untranslated sequence (8).

There are at least six important functional domains in the LPL protein that are likely to be coded for by different exons or combinations of exons in the LPL gene. The 27-amino acid signal peptide is encoded by exon 1 , which is cleaved from the mature protein after the second of three alanine residues $(6,8)$. The functional sites in the LPL protein include a domain for the interaction with apo CII, one for binding to membrane bound heparan sulfate, a catalytic site, a site promoting interaction with the other glycoprotein chain to form an active dimer and an interfacial lipid binding site. Our goal is to obtain new insights into the relationship between the structure and function of LPL by defining the molecular basis of naturally occurring mutations in the LPL gene.

We have previously described a deletion and duplication in the LPL gene each of which led to undetectable levels of LPL activity and LPL mass in plasma $(9,10)$. However, not all mutations would be expected to affect the LPL protein in the same way. The LPL protein may be catalytically defective but respond with a significant appearance of mass in plasma after heparin injection similar to that seen in normal persons. On the other hand, mutations that also effect heparan sulphate binding might result in elevated levels of LPL in preheparin plasma and show no increase after heparin injection (11).

The clinical syndrome of LPL deficiency presents with abdominal pain, pancreatitis, eruptive xanthomata, hepatosplenomegaly, and failure to thrive (12). LPL deficiency is a rare disorder occurring with a frequency of at least 1:1 million in most parts of the world (12). However, a significantly increased frequency of this disease has been found in French Canadians in certain regions of Quebec where the frequency of affected persons reaches between 1:5,000 and 1:10,000 with carrier frequencies of up to 1:40 (13).

Here we report the molecular basis for LPL deficiency on 21 alleles from 13 unrelated affected persons of different an- 
cestries including those of French Canadian, British, Dutch, Polish, and German descent. We also show that this same mutation underlies LPL deficiency in a family of non-European (East Indian) descent. A missense mutation in exon 5 resulting in an amino acid substitution of glycine for glutamic acid significantly impairs catalytic function.

\section{Methods}

Subjects. 19 French Canadian probands with LPL deficiency were ascertained through the Lipid Clinic of the Clinical Research Institute of Montreal and the Lipid Research Centre at Laval University Hospital. An additional 25 unrelated probands of different ancestries who were diagnosed with classical LPL deficiency were ascertained from colleagues in Canada, the United States, the Netherlands, and South Africa. Blood from 25 persons of French Canadian descent and 60 persons of other Caucasian ancestries was used as controls.

Measurement of LPL activity and mass. Plasma postheparin LPL activity was measured $10 \mathrm{~min}$ after a heparin bolus $(60 \mathrm{IU} / \mathrm{kg})$ after an overnight fast by using a triglyceride-phosphatidylcholine emulsion as previously described (14). LPL activity was calculated as the activity in whole plasma inhibited by an MAb (5D2) added to plasma (14) and is expressed as nanomoles of fatty acids released per minute per milliliter of plasma. The LPL preheparin and mass released into plasma by heparin were measured by ELISA using MAb 5D2 and is reported as nanograms/milliliter (15). The protein analyses were performed in Seattle and the DNA studies in Vancouver.

DNA analysis. Genomic DNA was extracted from white blood cells of LPL deficient probands and their family members for analysis by the polymerase chain reaction. The reactions were performed in a DNA thermocycler (Perkin-Elmer Cetus Corp., Cherry Hill, NJ) using the recommended buffer $200 \mu \mathrm{M}$ deoxynucleotide triphosphates (dNTPs), $1 \mu \mathrm{M}$ of each primer, $500 \mathrm{ng}$ genomic DNA, and $2.5 \mu \mathrm{m}$ thermostable DNA polymerase from thermus aquaticus (Cetus Corp.) in $100-\mu 1$ reactions.

The oligonucleotide primers were either synthesized in a DNA synthesizer (model 280A; Applied Biosystems, Inc., Foster City, CA) or the gene assembler Plus (Pharmacia Fine Chemicals, Piscataway, $\mathrm{NJ}$ ). Each exon of the LPL gene was individually amplified from $1 \mu \mathrm{g}$ of genomic DNA from a French Canadian and an Indian proband with LPL deficiency (Fig. 1). The reactions were denatured at $94^{\circ} \mathrm{C}$ for 1 min and annealed for $1 \mathrm{~min}$ at 50 or $60^{\circ} \mathrm{C}$ for different oligomers as shown in Table $\mathrm{I}$. The reactions were extended at $72^{\circ} \mathrm{C}$ for $1 \mathrm{~min}$ for a total of 30 cycles.

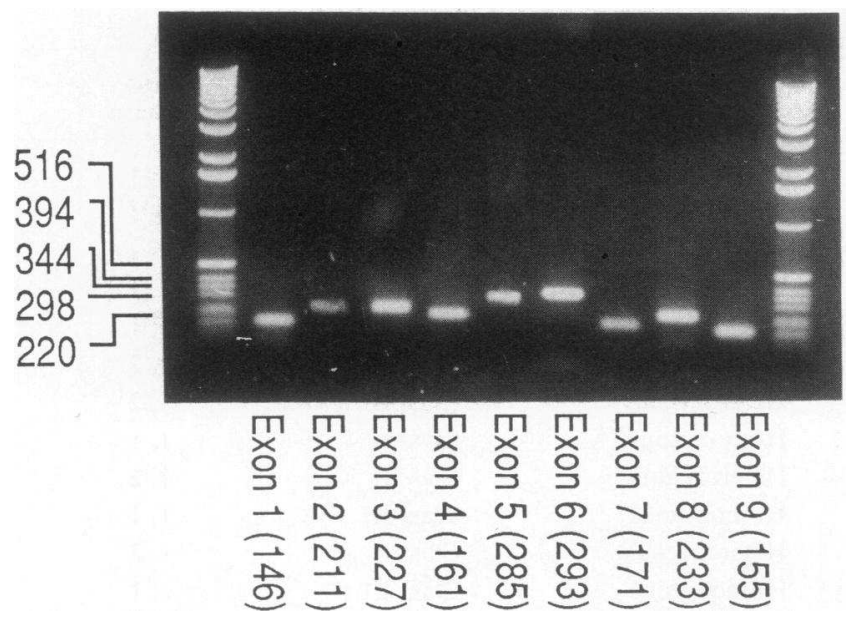

Figure 1. The exons of the entire coding sequence were amplified and the amplification products of the appropriate and expected size were subjected to direct sequencing.
Table I. Sequence and Annealing Temperature of the 5' and 3' Oligomers Flanking Exons of the LPL Gene

\begin{tabular}{|c|c|c|}
\hline Exon & Sequence & $\begin{array}{l}\text { Annealing } \\
\text { temperature }\end{array}$ \\
\hline & & ${ }^{\circ} \mathrm{C}$ \\
\hline \multirow[t]{2}{*}{1} & LPL- 1 5' CCTTGCAGCTCCTCCAGAGGG $3^{\prime}$ & 60 \\
\hline & LPL- 7 5' AGGGGAGTTTGCGCGCAAAA 3' & 60 \\
\hline \multirow[t]{2}{*}{2} & LPL- 8 5' CTCATATCCAATTTTTCCTT 3' & 50 \\
\hline & LPL- 9 5' CTCTTCCCCAAAGAGCCTCC $3^{\prime}$ & 50 \\
\hline \multirow[t]{2}{*}{3} & LPL-10 5' AAGCTTGTGTCATCATCTTC $3^{\prime}$ & 60 \\
\hline & LPL-11 5' ATAAGTCTCCTTCTCCCAGT 3' & 60 \\
\hline \multirow[t]{2}{*}{4} & LPL-30 5' TTTTGGCAGAACTGTAAGCA 3' & 50 \\
\hline & LPL- 31 5' GACAGTCTTTTCACCTCTTA 3' & 50 \\
\hline \multirow[t]{2}{*}{5} & LPL- $145^{\prime}$ TGTTCCTGCTTTTTTCCCTT 3' & 60 \\
\hline & LPL-15 5' TAATTCGCTTCTAAATAATA 3' & 50 \\
\hline \multirow[t]{2}{*}{6} & LPL-29 5' GCCGAGATACAATCTTGGTG 3' & 60 \\
\hline & LPL- 5 5' GCATGATGAAATAGGACTCC $3^{\prime}$ & 60 \\
\hline \multirow[t]{2}{*}{7} & LPL- 19 5' CATGTTCGAATTTCCTCCCC 3' & 60 \\
\hline & LPL-40 5' ATGACCGCCCCCCTGTGCTA $3^{\prime}$ & 60 \\
\hline \multirow[t]{2}{*}{8} & LPL-21 5' CCAAATTTATTGCTTTTTTG $3^{\prime}$ & 50 \\
\hline & LPL-22 5' AAGGAAGAAAAATACATTTA $3^{\prime}$ & 50 \\
\hline \multirow[t]{2}{*}{9} & LPL-23 5' TATTCACATCCATTTTCTTC $3^{\prime}$ & 50 \\
\hline & LPL- 24 5' GTCAGCTTTAGCCCAGAATG 3' & 50 \\
\hline
\end{tabular}

The primers used were complementary to $20 \mathrm{bp}$ of intron sequence flanking each exon. The selected sequence for the $5^{\prime}$ and the $3^{\prime}$ oligomers of each exon are modified from references 8 and 10 or are from unpublished data and are listed in Table I.

The polymerase chain reaction (PCR) products from three $100-\mu 1$ reactions were pooled, precipitated with $\mathrm{NH}_{4} \mathrm{OAc}$ /ethanol and size fractionated in a $1.2 \%$ agarose gel. The band corresponding to the amplified exon sequence was excised and purified using Geneclean (Bio 101, La Jolla, CA) and resuspended in $30 \mu \mathrm{l} \mathrm{H}_{2} \mathrm{O}$.

Two aliquots of $75 \mathrm{ng}$ were subjected to single-strand synthesis by a second round of amplification with 40 cycles using $660 \mathrm{ng}$ of the $5^{\prime}$ and 3 ' oligomer, respectively. The denatured, annealing, and extension conditions were as used for double-strand synthesis.

Reaction products were precipitated by $\mathrm{NH}_{4} \mathrm{OAc} /$ ethanol, washed in $70 \%$ ethanol and resuspended in $10 \mu \mathrm{l} \mathrm{H}_{2} \mathrm{O}$. Aliquots of $7 \mu \mathrm{l}$ were subjected to DNA sequencing using the Sequenase version 2.0 kit (U. S. Biochemicals Corp., Cleveland, $\mathrm{OH}$ ) and $1 \mathrm{pmol}$ of sequencing primer of opposite sense to the primer used in the amplification of single-stranded DNA.

The restriction fragment length polymorphisms (RFLP) around the mutations were determined after digestion of genomic DNA with Bam HI (16), Hind III (16), and Pvu II (17) and hybridized as previously described (9). The digested DNA was run on a $0.7 \%$ agarose gel, depurinated, denatured, and transferred to nylon filters (Nytran, Schleicher \& Schuell, Keene, NH). Prehybridization and hybridization were performed in the solutions as described previously (9). A 1.36-kb cDNA clone (HLP26) that corresponds to nucleotides 271-1,630 of the published cDNA sequence was used in the hybridization reactions $(2,9)$.

\section{Results}

Mutation analysis. Pedigrees were constructed for all probands. No genetic relationship was found between any of the affected probands with LPL deficiency in different families over a minimum of two generations.

The only change from normal seen in DNA from the proband of French Canadian (French Canadian 1) and East In- 


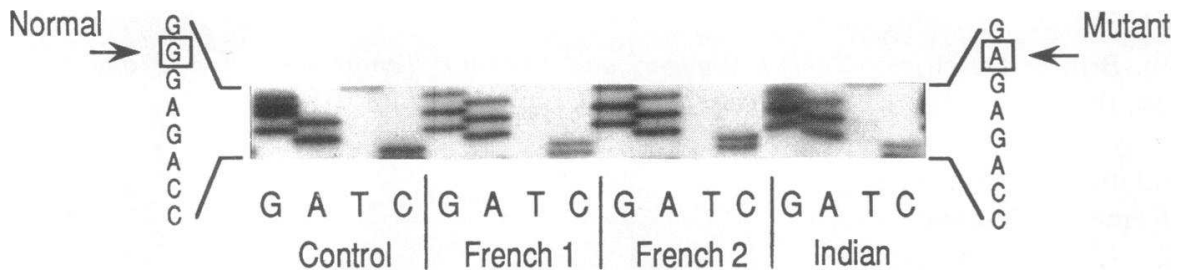

Figure 2. A G to A substitution at nucleotide 819 of the cDNA sequence predicts an amino acid change at residue 188 of glycine to glutamic acid.

dian (Asian) descent was a single basepair substitution (guanine to adenine), which was identified at nucleotide 819 of the cDNA sequence. This would predict an amino acid change of glutamic acid for glycine at residue 188. Exons 4-7 were also amplified from another affected person of French Canadian descent (French Canadian 2). A similar single-basepair substitution was detected (Fig. 2, Table II)

This nucleotide change abolishes an Ava II site within exon 5. PCR amplified exon 5 from a normal control and an affected person (French Canadian 2) and an obligate heterozygote for LPL deficiency (offspring of French Canadian 2) was digested with Ava II and run on an acrylamide gel. The predicted fragment sizes for normal and mutant DNA are shown in Fig. 3, $A$ and $B$. The expected fragment sizes were indeed observed, confirming that the mutation is present in the PCR products.

To confirm that this mutation was represented in genomic DNA and to determine how frequently this mutation caused LPL deficiency in French Canadians an additional 34 mutant alleles from 17 apparently unrelated French Canadians with LPL deficiency were assessed by Southern blot analysis with the LPL cDNA (9). A second Ava II site is present $\sim 660$ bp $3^{\prime}$ of exon 5 within intron 5 . The expected fragment sizes in a normal and a heterozygous person are shown in Fig. $4 \mathrm{~A}$. In total, 11 of 38 French Canadian mutant alleles were found to contain the same single nucleotide substitution (Fig. $4 \mathrm{~B}$, Table II). An additional 50 alleles from 24 unrelated persons of Dutch, East Indian, Javanese, Columbian, Turkish, English, and Polish descent were examined. All these patients had demonstrated LPL deficiency with measured LPL activity levels at $<6 \mathrm{nmol} / \mathrm{min}$ per $\mathrm{ml}$ in each instance (normal $200 \pm 59 \mathrm{nmol} /$ min per $\mathrm{ml}, 99 \%$ confidence interval 69-371) (15). The same mutation was detected in 10 LPL mutant alleles from 6 affected persons of Dutch, English, German and East Indian ancestry (Table I). Therefore 21 of a total of 88 mutant alleles examined from 44 unrelated patients with LPL deficiency were found to have the same mutation at residue 188 of the LPL protein (Table II).

The nucleotide substitution predicting the described amino acid change was not seen in any of 50 control French Canadian alleles or 120 LPL alleles from normolipidemic Caucasians using Ava II digestion and southern blot analysis.

Haplotype analysis. DNA haplotypes were constructed for 45 affected persons by using DNA from parents and other family relatives where appropriate. A total of seven different haplotypes at this locus were constructed. All chromosomes with the residue 188 mutation have the same DNA haplotype (haplotype 1) (Tables II and III). However, this haplotype also includes eight affected chromosomes that do not carry this mutation. It is of interest that all 4 chromosomes with the partial duplication of exon 6 causing LPL deficiency have the same haplotype (haplotype 2) (10) and the chromosome, which has previously been demonstrated to have a deletion of exons $3-5$ is the only chromosome bearing haplotype 3 (9) (Table III).

Two additional haplotypes were seen in the affected French Canadians without this mutation (data not shown). This suggests that there are likely to be at least three mutations underlying the high frequency of LPL deficiency in Quebec.

The mutant allele on haplotype 1 showed cosegregation with the clinical and biochemical LPL phenotype in the Indian family with LPL deficiency (Fig. 5 and Table IV). Persons who are missing Ava II sites in their fifth exon on both alleles (homozygous for the 188 mutation) and have haplotype I and

Table II. Unrelated Probands with the Acid Substitution of Glutamic Acid for Glycine at Residue 188 of the LPL Gene

\begin{tabular}{clclcr}
\hline $\begin{array}{c}\text { Patient } \\
\text { No. }\end{array}$ & Origin & Consanguinity & $\begin{array}{c}\text { Amino acid 188 } \\
\text { mutation }\end{array}$ & $\begin{array}{c}\text { Protein } \\
\text { defect* }\end{array}$ & $\begin{array}{c}\text { DNA } \\
\text { haplotype }\end{array}$ \\
\hline LPL 1 & FC & Yes & Homozygous & Class II & 1,1 \\
LPL 2 & FC & Yes & Homozygous & Class II & 1,1 \\
LPL 5 & FC & No & Heterozygous & Class II & 1,1 \\
LPL 6 & FC & No & Homozygous & Class II & 1,1 \\
LPL 7 & FC & No & Homozygous & Class II & 1,1 \\
LPL 11 & FC & No & Heterozygous & Class III & 1,2 \\
LPL 14 & FC & No & Heterozygous & Class II & 1,2 \\
LPL 24 & Indian & Yes & Homozygous & Class II & 1,1 \\
LPL 36 & English/Irish & No & Heterozygous & Class II & 1,2 \\
LPL 39 & English & Yes & Homozygous & Class II & Class II \\
LPL 42 & German & No & Heterozygous & Class III \\
LPL 46 & Polish & No & Homozygous & Class II & 1,2 \\
LPL 52 & Dutch & No & Homozygous & 1,1 \\
\end{tabular}

* Reference 11. FC, French Canadian. 
EXON $5(235$ bp)

\begin{tabular}{|lllll}
\hline 15 & 87 & Ava II & \\
\hline
\end{tabular}

EXON 5 (235 bp)
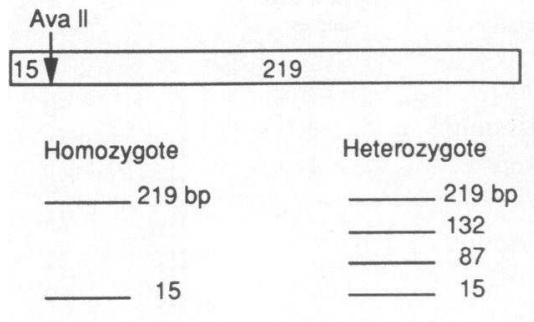

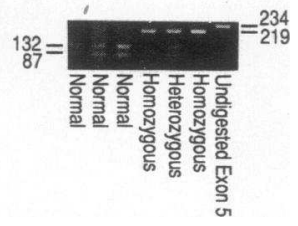

Figure 3. (Left and right) PCR-amplified exon 5 digested with Ava II normally results in fragment sizes of 132, 87, and 15 bp, respectively. This missense mutation at residues 188 abolishes an Ava II site resulting in fragments of 219 and $15 \mathrm{bp}$, respectively.

have the clinical and biochemical phenotype of LPL deficiency (Table IV and Fig. 5). Heterozygotes for the mutant LPL allele in this family have either mildly raised or normal lipid values compatible with the heterozygous state (Table IV). Details concerning a subset of this family have been published previously $(18,19)$.

The mutation at residue 188 of the LPL protein, occurs in a region that shows complete homology with the predicted amino acid sequence of guinea pig, mouse, and bovine LPL (20).

Protein results. Pre- and postheparin plasma LPL from 44 affected persons with LPL deficiency were assessed for LPL activity and mass. We selected all unrelated probands who had deficiency of LPL activity. 13 probands had at least one mutation at residue 188 (Table V), 8 persons were homozygous, and 5 were heterozygous for the mutation.

Seven of eight patients homozygous for the substitution of glutamic acid for glycine at residue 188 had incremental LPL enzyme protein in postheparin plasma. This displacement of endothelial bound enzyme into plasma with heparin implies normal heparin binding of the catalytically defective protein and has been defined previously as a class II defect (11). One person homozygous for the 188 mutation and one heterozygote had a class III protein defect in which the catalytically defective protein apparently does not bind to heparin (Table II).

\section{Discussion}

In this paper, we report that a substitution of glutamic acid for glycine in exon 5 of the LPL gene occurs on 21 of 88 alleles from 44 unrelated probands with LPL deficiency.
The demonstration that this mutation was the only change detected in the total sequence of the gene of one affected French Canadians and one Indian proband and was not present in 50 LPL alleles from normal French Canadian and 120 other Caucasians, favors this mutation as the cause of LPL deficiency in these families. The cosegregation of the mutant allele with the phenotypic expression of LPL deficiency in the Indian family (Fig. 5) supports this contention. In addition this same DNA alteration is found on 21 chromosomes from 13 unrelated affected persons and 7 affected siblings (data not shown) and never seen in a control without LPL deficiency which argues against this being a polymorphism linked to the mutant gene. Finally the location of this mutation within the longest segment of homology for LPL amongst human, cow, mouse, and guinea pig (20) further suggests that this is a region of considerable biological significance. Therefore, from the data currently available it appears likely that the missense mutation at amino acid 188 is responsible for the LPL deficiency.

LPL deficiency occurs with the highest reported worldwide frequency in the French Canadian population. The frequency in the counties of Charlevoix and Saguenay-Lac St. Jean is $\sim 100-200$ times the estimated worldwide frequency of 1 in 1 million (13). The presence of the mutation at residue 188 of the LPL protein in a significant proportion of French Canadian probands suggests a founder effect. The majority of French Canadians are descendants of 8,000 settlers who migrated from Brittany, Normandy, and the western provinces of France between 1608 and 1763 . There was little additional migration from France after that time and intermarriage with persons of Anglo-Saxon descent was limited (21). The presence of a mutation in one of the founding settlers together with the presence of large families and consanguinity would be ex-

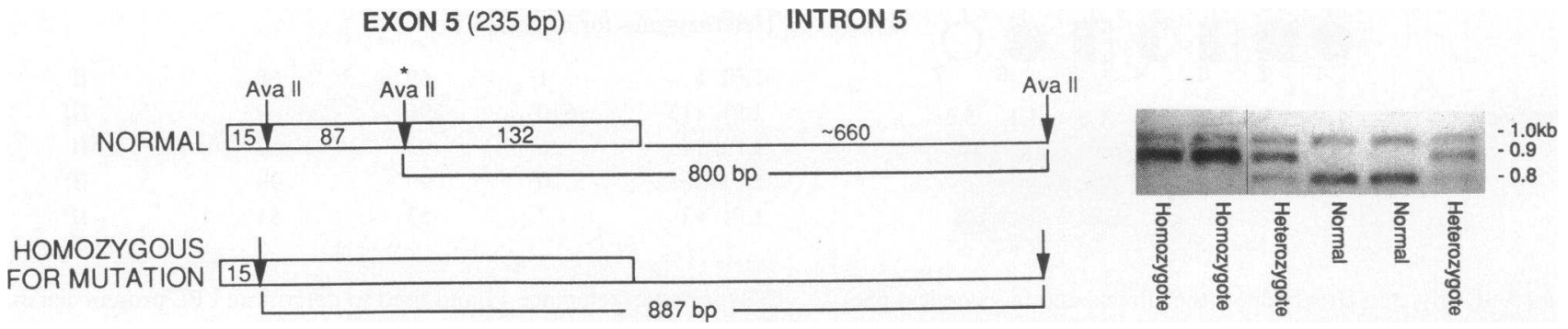

Figure 4. (Left and right) The missense mutation in exon 5 alters the expected Southern blot fragment pattern with loss of the Ava II site and resultant increase in the normal fragment size from 800 to $887 \mathrm{bp}$, respectively. 
Table III. Haplotypes at the LPL Locus Associated with Mutations in the LPL Gene

\begin{tabular}{cccccc}
\hline Haplotype & Hind III & Bam HI & Pvu II & Mutation & $\begin{array}{c}\text { No. of mutant } \\
\text { alleles }\end{array}$ \\
\hline 1 & + & - & - & AA 188 & 21 \\
2 & + & - & + & Duplication*t & 4 \\
3 & - & + & + & Deletion* & 1 \\
4 & - & - & + & - & - \\
5 & + & + & - & - & - \\
6 & - & + & - & - & - \\
7 & + & + & + & - & - \\
8 & - & - & - & - & - \\
\hline
\end{tabular}

* Reference 8 ; ${ }^{\ddagger}$ reference 9.

+ , presence; - , absence of restriction site.

pected to result in a very high frequency for this disease in the population. Evidence in support of this is the high frequency of tyrosinemia (22), vitamin D deficiency (22), and familial hypercholesterolemia (23) in this population group.

The presence of the same mutation in a family of non-European ancestry is interesting. The grandparents of the proband of Indian descent were born in the villages of Furus and Sakhrol near Khed, which is close to Bombay. There is no obvious relationship between any of the families of European descent and this Indian kindred. The ancestries of the other families with this mutation are English, Irish, German, Polish, and Dutch for many generations. Either this mutation has occurred spontaneously more than once at this position of the gene or one needs to postulate a common ancestor. However, the nucleotide sequence in this region is not typical for sequences rich in CpG dimers, which may be hotspots for mutations (24).

At least three RFLPs have been described at the LPL gene locus $(16,17)$. A total of eight DNA haplotypes are possible using a combination of these three RFLPs. 7 haplotypes were represented in this group of 44 unrelated probands with LPL deficiency. It is noteworthy that there was complete concordance between the residue 188 mutation and haplotype 1 .

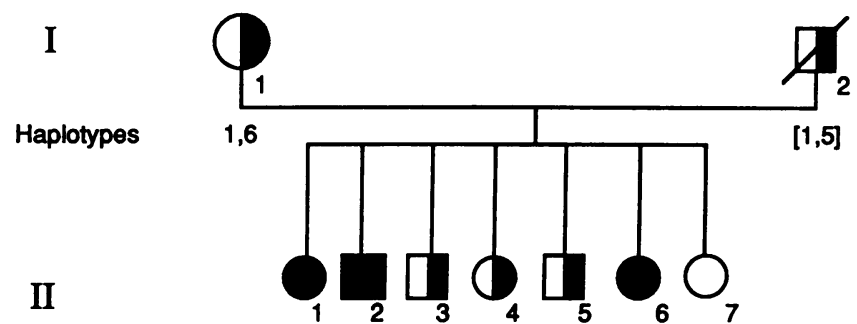

Haplotypes

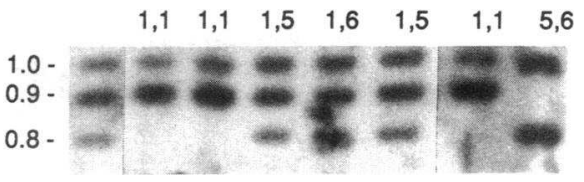

Figure $5 . \mathrm{II}_{1}, \mathrm{II}_{2}$, and $\mathrm{II}_{6}$ who have the clinical and biochemical phenotype of LPL deficiency have absence of the 800-bp fragment on both alleles. The obligate heterozygote $\left(I_{1}\right)$ has an 800 - and 887-bp Ava II fragment. The haplotype in the father has been reconstructed.
Table IV. Lipid Values and Ages in the Indian Family with LPL Deficiency

\begin{tabular}{lcccl}
\hline & Age & Triglyceride & Total cholesterol & Genetic status \\
\hline & $y r$ & \multicolumn{3}{c}{ mmol/liter } \\
$\mathrm{I}_{1}$ & 50 & 1.72 & 6.1 & Heterozygote \\
$\mathrm{II}_{1}$ & 27 & 53.9 & 13.0 & Homozygote \\
$\mathrm{II}_{2}$ & 26 & 49.2 & 12.8 & Homozygote \\
$\mathrm{II}_{3}$ & 25 & 3.17 & 6.21 & Heterozygote \\
$\mathrm{II}_{4}$ & 21 & 1.61 & 7.08 & Heterozygote \\
$\mathrm{II}_{5}$ & 19 & 1.25 & 5.35 & Heterozygote \\
$\mathrm{II}_{6}$ & 15 & 37.6 & 7.16 & Homozygote \\
$\mathrm{II}_{7}$ & 13 & 1.1 & 4.6 & Normal
\end{tabular}

Probands with two other previously described mutations have haplotypes 2 and 3 respectively $(9,10)$ (Table III). DNA haplotype analysis allowed us to address the question as to whether this single mutation has a common origin with geographical distribution after migration or whether the mutation has multicentric independent origins. The demonstration of a single haplotype underlying this mutation is preliminary evidence for a common origin for this mutation predating the spread of European and Indian populations. Haplotype 1 is also seen in probands who do not have this mutation and the population frequencies of these haplotypes are not known.

The high frequency of this mutation in French Canadians and other persons with LPL deficiency allows development of a rapid screening test for this mutation using PCR and diges-

Table V. LPL Immunoreactive Mass in LPL-deficient Patients with the Amino Acid 188 Mutation

\begin{tabular}{lllll}
\hline & \multicolumn{2}{c}{ LPL mass } & \\
\cline { 2 - 3 } Patient No. & $0^{\prime}$ & $10^{\prime}$ & Increment & Protein class* \\
\hline & & $n g / m l$ & &
\end{tabular}

Homozygotes for mutation

$\begin{array}{lrrrl}\text { LPL 1 } & 30 & 98 & 68 & \text { II } \\ \text { LPL 2 } & 1 & 36 & 35 & \text { II } \\ \text { LPL 6 } & 19 & 42 & 23 & \text { II } \\ \text { LPL 7 } & 30 & 98 & 68 & \text { II } \\ \text { LPL 24 } & 1 & 78 & 77 & \text { II } \\ \text { LPL 39 } & 12 & 56 & 44 & \text { II* } \\ \text { LPL 46 } & 96 & 86 & - & \text { III* } \\ \text { LPL 52 } & 18 & 82 & 64 & \text { II }\end{array}$

Heterozygotes for mutation

$\begin{array}{lrrll}\text { LPL 5 } & 1 & 69 & 68 & \text { II } \\ \text { LPL 11 } & 610 & 596 & - & \text { III } \\ \text { LPL 14 } & 26 & 93 & 67 & \text { II } \\ \text { LPL 36 } & 0 & 99 & 99 & \text { II** } \\ \text { LPL 42 } & 2 & 53 & 51 & \text { II* }^{*}\end{array}$

* Reported in reference 11 and used to determine LPL protein classification system.

${ }^{\ddagger}$ Sibling has same haplotype, LPL mass 0 at $0^{\prime}$ and $100 \mathrm{ng} / \mathrm{ml}$ at $10^{\prime}$. Both have exon 6 duplication involving other alleles. 
tion with Ava II and assessment using either Southern blot analysis (Fig. 4) or running the amplified fragments on an acrylamide gel (Fig. 3). Alternatively, a very rapid approach to diagnosis of this mutation can be undertaken using allele specific oligonucleotides for the normal and mutant alleles (data not shown).

Human LPL deficiency recently has been classified at the protein level on the basis of the absence (Class I) or presence of defective enzyme protein, and whether it binds (Class II) or does not bind (Class III) to heparin (11). We have previously described the molecular basis of LPL deficiency in one Class I patient with no identifiable LPL activity nor mass (10). 7 of the 23 LPL-deficient patients previously reported were Class II (15). DNA was available in four of these Class II individuals from three families and they were either homozygous $(n=1)$ or heterozygous $(n=3)$ for the 188-point mutation. 11 of the 13 patients in the present manuscript with the 188-point mutation were Class II. However, two patients had Class III protein defects. One of these patients was homozygous and one was heterozygous for the 188 mutation. One might explain the Class III protein in the heterozygote as the product of the other allele, but it is difficult to explain the presence of the Class III protein in the patient who is homozygous for the 188 mutation if one attempts to correlate the 188 mutations solely with a Class II defect. It is possible that an otherwise silent mutation may effect heparin binding in the presence of the homozygous 188 mutation. The presence of an additional variation in the gene that might effect tertiary structure and heparin binding needs to be explored by sequencing the remainder of the gene of this patient.

The clinical presentation of LPL deficiency is varied (12). Most cases are detected in the first decade of life but diagnosis even in the sixth decade has occurred. Environmental factors, especially dietary intake and pregnancy, may modulate the clinical phenotype. However, it is also possible that different mutations in the same gene will result in different clinical phenotypes. Examples include the less severe presentation of Becker muscular dystrophy compared with Duchenne muscular dystrophy with mutations in the same gene (25). The characterization of a common mutation underlying LPL deficiency in the French Canadian population and other persons with LPL deficiency will allow examination of the relationship of this specific genotype to the clinical phenotype.

The study of mutations in the LPL gene is likely to provide clues as to which regions of the LPL protein are crucial for specific functions. Furthermore, species conservation provides additional evidence for biological significance of certain regions. The two largest segments of the LPL protein that share complete homology between human, guinea pig, mouse, and cow are residues $178-210$ in exon 5 and residues $287-320$ which span part of exon 6 and 7 (6). It has previously been demonstrated that the heparin binding site is likely to be located between amino acid residues 292 and 307 with the candidate segment being $\mathrm{Lys}_{292}-\mathrm{Lys}_{300}$, which has five positively charged amino acid residues and is encoded by exon $6(8,20)$.

It is noteworthy that human and rat hepatic lipase share complete homology with residues $182-187$ of human, guinea pig, mouse, and bovine LPL (6). The predicted amino acid substitution of glutamic acid for glycine extends the homology between abnormal (mutant) human LPL and human and rat hepatic lipase for an additional residue (Fig. 6). It is interesting that this substitution is critical for catalytic activity in human

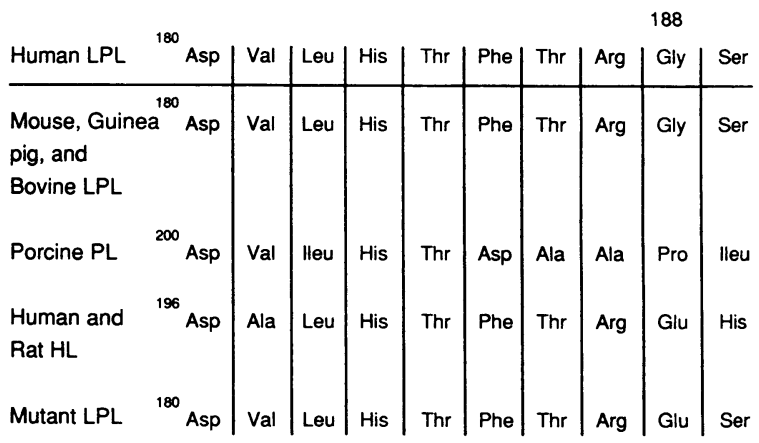

Figure 6. LPL of all species shares complete homology with human and rat hepatic lipase between residues 182-187 (19). The missense mutation at residue 188 of LPL altering glycine to glutamic acid further extends the homology with hepatic lipase for an additional residue.

LPL but does not affect normal catalytic activity of hepatic lipase (data not shown). This may further suggest that this residue is not the active site for LPL or any other lipase but effects catalytic activity through an indirect mechanism.

The amino acid substitution of glutamic acid for glycine alters the charge of the molecule and significantly impairs catalysis. However, this is not the catalytic site. Biochemical and structural evidence indicate that the triad formed by Ser 152 , His 263, and Asp 176 represents the lipolytic site for human pancreatic lipase (26). The active site Ser 152 (which corresponds to Ser 132 in hLPL) is blocked by a loop between residues 237 to 261 . Repositioning of this loop is necessary to allow accessibility of the active site to substrate and may be influenced by side chains in intimate contact with the loop (26). The mutation at residue 188 described in this manuscript does not affect the catalytic site but may influence catalysis by modulating accessibility of the substrate to the active site of hLPL by affecting tertiary structure. The three-dimensional structure of hLPL is likely to provide answers to some of these questions.

\section{Acknowledgments}

We thank our colleagues Drs. J. Witzum, J. Bergeron, A. D. Bharucha, D. Brun, A. Stalenhoef, P. Stuyt, J. Frohlich, and G. M. B. Berger for giving us access to samples from their patients.

This work was supported by the British Columbia Heart Foundation and National Institute of Health Grants HL-30086, GM-15253, and DK-02456. Dr. P. Julien is a career scientist of the Fonds de la Recherche en Santé du Quebec. Dr. Michael Hayden is an Investigator of the British Columbia Children's Hospital.

\section{References}

1. Iverius, P. H., and A. M. Ostlund-Lindquist. 1976. Lipoprotein lipase from bovine milk. Isolation procedure, chemical characterization and molecular weight analysis. J. Biol. Chem. 251:7791-7795.

2. Wion, K. L., T. G. Kirchgessner, A. J. Lusis, M. C. Schotz, and R. M. Lawn. 1987. Human lipoprotein lipase complementary DNA sequence. Science (Wash. DC). 235:1638-1641.

3. Senda, M., K. Oka, W. V. Brown, P. K. Qasba, and Y. Furuichi. 1987. Molecular cloning and sequence of a cDNA coding for bovine lipoprotein lipase. Proc. Natl. Acad. Sci. USA. 84:4369-4373.

4. Kirchgessner, T. G., K. L. Svenson, A. J. Lusis, and M. C. 
Schotz. 1987. The sequence of the cDNA encoding human lipoprotein lipase: a member of a lipase gene family. J. Biol. Chem. 262:84638466.

5. Enerback, S., H. Semb, G. Bengtsson-Olivecrona, P. Carlsson, M. L. Hermansson, T. Olivecrona, and G. Bjarsell. 1987. Molecular cloning and sequence,analysis of cDNA encoding lipoprotein lipase of guinea pig. Gene (Amst.). 58:1-12.

6. Semenkovich, C. F., S. H. Chen, M. Wims, C. C. Luo, W. H. Li, and L. Chan. 1989. Lipoprotein lipase and hepatic lipase mRNA tissue specific expression, developmental regulation and evolution. J. Lipid Res. 30:423-431.

7. Sparkes, R. S., S. Zollman, I. Klisak, T. G. Kirchgessner, M. C. Komaromy, T. Mohandas, M. C. Schotz, A. J. Lusis. 1987. Human genes involved in lipolysis of plasma lipoproteins: mapping of loci for lipoprotein lipase to $8 \mathrm{p} 22$ and hepatic lipase to $15 \mathrm{q} 21$. Genomics. 1:138-144.

8. Deeb, S. S., and R. Peng. 1989. Structure of the human lipoprotein lipase gene. Biochemistry. 28:4131-4135.

9. Langlois, S., S. Deeb, J. D. Brunzell, J. J. Kastelein, and M. R. Hayden. 1989. A major insertion accounts for a significant proportion of mutations underlying human lipoprotein lipase deficiency. Proc. Natl. Acad. Sci. USA. 86:948-952.

10. Devlin, B., S. Deeb, J. D. Brunzell, and M. R. Hayden. 1990. Partial gene duplication involving exon-alu interchange results in lipoprotein lipase deficiency. Am. J. Hum. Genet. 46:112-119.

11. Auwerx, J. H., S. P. Babirak, W. Y. Fujimoto, P. H. Iverius, and J. D. Brunzell. 1989. Defective enzyme protein in lipoprotein lipase deficiency. Eur. J. Clin. Invest. 19:433-437.

12. Brunzell, J. D. 1989. Familial lipoprotein lipase deficiency and other causes of the chylomicronemia syndrome. In Metabolic Basis of Inherited Disease. 6th ed. C. R. Scriver, A. L. Beaudet, W. S. Sly, and D. Valle, editors. McGraw-Hill Book Co., New York. 1165-1180.

13. Gagne, C., L. D. Brun, P. Julien, S. Moorjani, and P. J. Lupien. 1989. Primary lipoprotein lipase activity deficiency: clinical investigation of a French Canadian population. CMAJ (Can. Med. Assoc. J.) 140:405-411.

14. Iverius, P. H., and J. D. Brunzell. 1985. Human adipose tissue lipoprotein lipase: changes with feeding and relation to post heparin plasma. Am. J. Physiol. 249:E107-E114.

15. Babirak, S. P., P. H. Iverius, W. Y. Fujimoto, and J. D. Brun- zell. 1989. Detection and characterization of the heterozygote state for lipoprotein lipase deficiency. Arteriosclerosis. 9:326-332.

16. Fisher, K. L., G. A. Fitzgerald, and R. M. Lawn. 1987. Two polymorphisms in the human lipoprotein lipase (LPL) gene. Nucleic Acids Res. 15:7657.

17. Funke, H., J. Klug, and G. Assmann. 1987. Hind III RFLP in the lipoprotein lipase gene (LPL). Nucleic Acids Res. 15:9102.

18. Berger, G. M. B., and F. Bonnici. 1977. Familial hyperchylomicronaemia in four families. S. Afr. Med. J. 51:623-628.

19. Berger, G. M. B. 1987. Clearance defects in primary chylomicronemia: a study of tissue lipoprotein lipase activities. Metab. Clin. Exp. 35:1054-1061.

20. Persson, B., G. Bengtsson-Olivecrona, S. Enerback, T. Olivecrona, and H. Jornvall. 1989. Structural features of lipoprotein lipase. Eur. J. Biochem. In press.

21. Laberge, C. 1966. Prospectus for genetic studies in French Canadians with preliminary data on the blood groups and consanguinity. Bull. Johns Hopkins Hosp. 118:52-68.

22. Bouchard, G., C. Laberge, and C. Scriver. 1985. La tyrosinémie héréditarie et le rachitisme vitamo-dépendant au Saguenay. Une approche génétique et démographique. Union Med. Can. 114:633-636.

23. Hobbs, H. H., M. S. Brown, D. W. Russell, J. Davignon, and J. L. Goldstein. 1987. Deletion in the gene for the low-density-lipoprotein receptor in a majority of French Canadians with familial hypercholesterolemia. N. Engl. J. Med. 317:734-737.

24. Barker, D., M. Schafer, and R. White. 1984. Restriction sites containing $\mathrm{CpG}$ show a higher frequency of polymorphism in human DNA. Cell. 36:131-138.

25. Koenig, M., A. H. Beggs, M. Moyer, S. Scherpf, K. Heindrich, T. Bettecken, G. Meng, C. R. Müller, M. Lindlöf, H. Kaariainen, A. de la Chapelle, A. Kiuru, M.-L. Savontaus, H. Gilgenkrantz, D. Récan, J. Chelly, J.-C. Kaplan, A. E. Covone, N. Archidiacono, G. Romeo, S. Liechti-Gallati, V. Schneider, S. Braga, H. Moser, B. T. Darras, P. Murphy, U. Francke, J. D. Chen, G. Morgan, M. Denton, C. R. Greenberg, K. Wrogemann, L. A. J. Blonden, H. M. B. van Paassen, G. J. B. van Ommen, and L. M. Kunkel. 1988. The molecular basis for Duchenne versus Becker muscular dystrophy: correlation of severity with type of deletion. Am. J. Hum. Genet. 45:498-506.

26. Winkler, F. K., A. D'Arcy, and W. Hunziker. 1990. Structure of human pancreatic lipase. Nature (Lond.). 343:771-774. 